\title{
Ebola Virus Disease Outbreak in Lagos, Nigeria; 2014: an Epidemiological Investigation
}

\author{
Folasade F. Osundina*, Abisola Oladimeji, Olufemi Ajumobi, Saheed Gidado, Adebola \\ T. Olayinka and Patrick M. Nguku
}

Nigeria Field Epidemiology and Laboratory Training Programme, Abuja, Nigeria

\section{Objective}

To describe the socio-demographic characteristics of Ebola virus disease (EVD) patients and their contacts, magnitude of the outbreak and factors associated with outcome in patients.

\section{Introduction}

West Africa recently experienced the most persistent epidemic of EVD recorded in history. The reported morbidity and mortality of the highly virulent, emerging zoonotic filovirus infection is far larger than all previous epidemics combined ${ }^{1}$. Its spread to Nigeria (Africa's most populous country) and to densely populated Lagos (a city in Nigeria with approximate combined population of Guinea, Sierra Leone, and Liberia) raised significant public health concern ${ }^{2}$. The Federal Ministry of Health was notified of a suspected case of viral haemorrhagic fever on the $22^{\text {nd }}$ July, 2014. A 40-year old male Liberian presented in a private health facility on account of fever, vomiting and diarrhea. On the $23^{\text {rd }} \mathrm{July}$, the index case was confirmed to have EVD and on $25^{\text {th }}$ July, he died.

\section{Methods}

An Emergency operation centre was set up on $25^{\text {th }}$ July, 2014. We adapted case and contact definitions from the World Health Organization (WHO) guidelines. Active case search in health facilities, communities, religious centers and various ports of entry into the country was done by well-trained epidemiologists and surveillance officers. We traced EVD contacts by contact identification, listing and active follow-up; taking daily temperature measurements and monitoring of symptoms to identify suspected cases. Laboratory confirmation of cases was done by reverse transcriptase-polymerase chain reaction. Prompt case management was commenced for positive cases with strict adherence to infection prevention and control measures. Data on socio-demographic characteristics, clinical symptoms and disease outcomes was collected using contact listing, contact follow-up, case listing forms and Open Data Kit (ODK) for real time data collation. Univariate and bivariate analysis was done.

\section{Results}

Fourteen out of the 16 cases identified $(87.5 \%)$ were contacts under follow-up. From these cases, 293 contacts were identified. None of the contacts was lost to follow-up. The mean age of cases and contacts were $39.1 \pm 11.9$ years and $33.2 \pm 13.9$ years respectively. Majority of the cases $(43.8 \%)$ and contacts $(33.0 \%)$ were aged $30-$ 39 years. Of the 16 cases, $8(50.0 \%)$ were females and $10(62.5 \%)$ were health workers. Of the 293 contacts 150 (52.0\%) were females and $138(47.0 \%)$ were health workers. Of the 15 cases traced to the index case, $13(86.7 \%)$ were first generation cases while $2(13.3 \%)$ were second generation cases. The case reproduction number for the outbreak was 13 and the secondary attack rate was $4.4 \%$. The most reported symptom was fever $(85.7 \%)$. Case fatality rate (CFR) among all the cases was $37.5 \%(6 / 16)$, while CFR among health workers was $40.0 \%(4 / 10)$. Health workers proportional mortality rate was $66.7 \%$ (4/6). The epidemic curve revealed a common source pattern at the early phase and a propagated pattern thereafter. Average duration of illness from onset of symptoms to survival and death was $16 \pm 4.8$ days and $11.6 \pm 5.0$ days respectively. There were no statistically significant association between the duration of illness and the outcome of disease (odds ratio $(\mathrm{OR})=1.14,95 \% \mathrm{CI}=0.08-16.95$ ), and between occupation of cases (health workers versus non-health workers $)$ and outcome $(\mathrm{OR}=1.33, \mathrm{CI}=0.16-11.08)$

\section{Conclusions}

Health care workers and the active age group were more affected during the outbreak. The outbreak was contained through effective contact tracing and surveillance. Duration of illness and occupation were not significantly associated with outcome

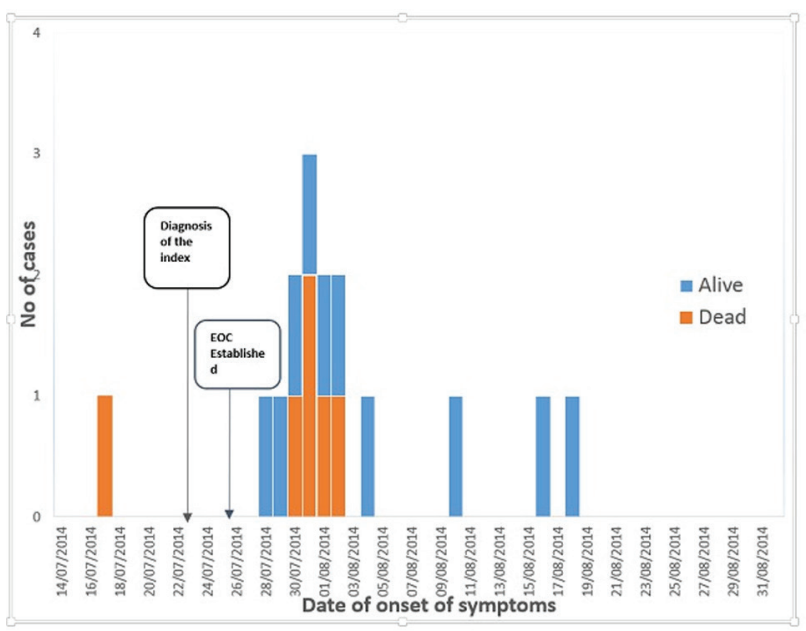

Figure: Epidemic curve of EVD in Lagos State, July to September, 2014

\section{Keywords}

Ebola virus disease; outbreak investigation; disease outcome; Lagos State

\section{References}

1.Bruce Aylward, Philippe Barboza, Luke Bawo, B.Pharm, Eric Bertherat, Pepe Bilivogui, Isobel Blake, Rick Brennan. Ebola Virus Disease in West Africa - The First 9 Months of the Epidemic and Forward Projections. $n$ engl j med 2014; 371(16):1481-95

2.Anthony S. Fauci. Ebola - Underscoring the Global Disparities in Health Care Resources. $n$ engl j med 371;12 nejm.org September 18, 2014

\section{*Folasade F. Osundina}

E-mail: sosundina@yahoo.com 